\title{
AUMENTO DA DISPONIBILIDADE E DA CONFIABILIDADE EM UM MÓDULO DESACELERADOR DE PRODUTOS
}

\section{INCREASED THE AVAILABILITY AND RELIABILITY IN A DECELERATOR PRODUCTS MODULE}

\author{
Doglas Stoffel $^{1}$; Juan Pablo Raggio Quintas ${ }^{2}$ \\ ${ }^{1}$ Universidade Federal do Rio Grande do Sul - RS - Brasil \\ doglasstoffel@gmail.com \\ ${ }^{2}$ Universidade Federal do Rio Grande do Sul - RS - Brasil \\ pablo@ufrgs.br
}

\begin{abstract}
Resumo
A manutenção, como função estratégica das organizações é responsável direta pela disponibilidade dos ativos, tem importância capital nos resultados da empresa. O objeto de estudo é um módulo de desaceleração de produtos de máquina de produção de produtos de higiene de uma companhia Multinacional localizado no Rio Grande do Sul, cuja máquina é a linha com maior capacidade produtiva da planta, correspondendo em cerca de $25 \%$ do volume de produção mensal e a manutenção corretiva neste módulo ocasiona perdas de produção significativas. O trabalho tem como objetivo aumentar a disponibilidade e a confiabilidade através da Manutenção Centrada na Confiabilidade (MCC) que se baseia na análise das falhas, uso da metodologia FMEA $e$ implementação das melhorias analisadas para reduzir a possibilidade de ocorrência de falhas $e$ garantir que o equipamento execute suas funções a custos mínimos. Após análise e implementação das ações geradas, o MTTF (Mean Time To Failure) passou de 57,7 horas para 1774,0 horas e y de 0,76 para 1,02, passando da fase de mortalidade infantil para a fase de maturidade, sem atingir a fase de desgaste ainda por falhas aleatórias no processo produtivo. Com isso, disponibilidade do equipamento passou $96,9 \%$ para $99,8 \%$.
\end{abstract}

Palavras-chave: disponibilidade; confiabilidade; FMEA.

\section{Introdução}

A partir da década de 70, a manutenção industrial começou a adquirir um grau de importância diferenciado. Fatores fundamentais das atividades industriais, relacionados com produção, qualidade e custos, passaram então a depender diretamente das condições de manutenção. A partir dos anos 90, com a globalização da economia e a consequente expansão dos mercados, impositivos de confiabilidade, disponibilidade, entre técnicas, filosofias e métodos a manutenção se tornou um processo integrante da organização (MUNIZ, 2010). 
A manutenção, como função estratégica das organizações é responsável direta pela disponibilidade dos ativos, tem importância capital nos resultados da empresa. Esses resultados serão tanto melhores quanto mais eficaz for a gestão da manutenção. Segundo dados estatísticos da Abraman (2003), o Brasil tem custo de manutenção por faturamento bruto de 4,3\% do PIB (Produto Interno Bruto) contra a média mundial de $4,1 \%$, isso significa para um PIB FGV (Fundação Getúlio Vargas) de US\$ 451 bilhões - representam 19 bilhões em gastos em manutenção. Portanto esta realidade demonstra que as organizações devem procurar as melhorias contínuas na sua gestão da manutenção, buscando-se incessantemente dos conhecimentos inovadores e aplicação das melhores práticas da manutenção já praticadas nas organizações dos países do primeiro mundo (OTANI, 2008).

O termo Manutenção Corretiva $^{1}$ é amplamente conhecido no ramo industrial e ainda é a forma mais comum de reparo de um equipamento com problema. Sua principal característica é que o conserto se inicia após a ocorrência da falha, dependendo da disponibilidade de mão de obra e material necessários para o conserto, falta de planejamento e custos necessários, bem como o desprezo pelas perdas de produção (PEREIRA, 2009).

Para Fogliatto\&Duarte (2009), as quebras e falhas conduzem à perda total ou à redução da capacidade produtiva do equipamento, isto é, reduz a disponibilidade do equipamento. Elas são o principal fator que influencia no rendimento operacional dos equipamentos e, portanto, devem ser combatidas.

A definição da melhor solução de manutenção deve ser analisada individualmente de equipamento para equipamento, levando em consideração sua taxa de falha, o custo de manutenção e o impacto da falha no sistema produtivo. Para Fogliatto\&Duarte (2009), o programa de Manutenção Centrada em Confiabilidade (MCC) tem se mostrado uma forma eficiente de tratar as questões de manutenção devido à sua abordagem racional e sistemática.

Portanto, é apropriado constatar que as atividades de manutenção respondem por custos em uma organização, mas a não conformidade da execução dos serviços de manutenção e a não manutenção envolvem outros custos muitas vezes mais importantes que os primeiros, como falta de segurança, paradas não previstas de equipamentos, perdas de matéria-prima, peças refugadas, horas extras, entre outras (MUNIZ, 2010).

O módulo de desaceleração de produtos da máquina de produção de produtos de higiene tem grande importância para o mantenimento e processo produtivo da planta fabril de uma companhia Multinacional localizado no Rio Grande do Sul, pois se trata de um ativo vital e único, isto é, sem back-up, e que participa diretamente do processo produtivo e sua falha ocasiona perda de função, de

\footnotetext{
${ }^{1}$ Manutenção Corretiva: manutenção efetuada após a ocorrência de uma pane destinada a recolocar um item em condições de executar uma função requerida (ABNT-NBR-5462-1994).
} 
produção e de faturamento. A máquina que contém este módulo é a linha com maior capacidade produtiva da planta, correspondendo em cerca de $25 \%$ do volume de produção mensal e a manutenção corretiva neste módulo ocasiona perdas de produção significativas.

Dessa forma, existe a oportunidade de analisar individualmente o módulo da máquina e obter como produto da manutenção a maior disponibilidade confiável ao menor custo, o que é garantido na execução dos serviços de manutenção de forma adequada e de acordo com as exigências técnicas (MUNIZ, 2010).

\section{Objetivos}

O trabalho tem como objetivo aumentar a disponibilidade e a confiabilidade através do estudo e aplicação de melhorias em um conjunto crítico de uma máquina de produção de produto de higiene. Para isso, têm-se os seguintes objetivos específicos:

- Analisar o histórico do equipamento e apresentar medidas de confiabilidade, descrição das possíveis falhas e respectivas causas;

- Sugerir ações que impeçam ou amenizem a ocorrência de possíveis falhas através de técnicas de engenharia;

- Implantar as melhorias específicas para aumentar a disponibilidade e confiabilidade do equipamento.

\section{Revisão bibliográfica}

\subsection{Conceitos}

\subsubsection{Manutenção}

Combinação de todas as ações técnicas e administrativas, incluindo as de supervisão, destinadas a manter ou recolocar um item em um estado no qual ele possa desempenhar uma função requerida (ABNT-NBR 5462/1994(2.81)).

\subsubsection{Manutenção corretiva}

Manutenção efetuada após a ocorrência de uma pane destinada a recolocar um item em condições de executar uma função requerida (ABNT-NBR-5462-1994).

\subsubsection{Manutenção preventiva}

Manutenção efetuada em intervalos predeterminados, ou de acordo com critérios prescritos, destinados a reduzir a probabilidade de falha ou a degradação do funcionamento do item (ABNTNBR-5462-1994). 


\subsubsection{Disponibilidade}

Para Fogliatto\&Duarte (2009), disponibilidade é definida como a capacidade de um item, mediante manutenção apropriada, desempenhar sua função requerida em um determinado instante de tempo ou em um período de tempo predeterminado. Em unidades reparáveis, os possíveis estados da unidade em um tempo t de análise são funcionando ou em manutenção, isto é, sofrendo reparo, sendo o valor médio de disponibilidade dado por:

$$
A=\frac{M T T F}{M T T F+M T T R}
$$

Onde A denota a disponibilidade média da unidade, MTTF é o tempo médio entre falhas e MTTR é o tempo médio de reparo.

\subsubsection{Confiabilidade}

A confiabilidade de um item corresponde a sua probabilidade de desempenhar o seu propósito especificado, por um determinado período de tempo e sob condições ambientais predeterminadas (FOGLIATTO\&DUARTE, 2009).

\subsection{Manutenção centrada em confiabilidade (MCC)}

Segundo a norma brasileira NBR 5462-1994, item 2.2.6.4, a confiabilidade de um item é a probabilidade de que este item desempenhe a função requerida, por um intervalo de tempo estabelecido, sob condições definidas de uso.

A base de um trabalho de um programa de MCC é a definição das funções e padrões de desempenho dos equipamentos, seguido da descrição de suas possíveis falhas, bem como da análise de suas causas, consequências e da definição de ações que impeçam ou amenizem sua ocorrência através de técnicas de engenharia para assegurar que os equipamentos de uma planta fabril continuarão realizando as funções especificadas. Dessa forma, a MCC permite que as empresas alcancem excelência nas atividades de manutenção, ampliando a disponibilidade dos equipamentos e reduzindo custos associados a acidentes, defeitos, reparos e substituições (FOGLIATTO\&DUARTE, 2009).

A função de risco ou taxa de falha $h(t)$ pode ser considerada a medida de confiabilidade mais difundida na prática. Tal função pode ser interpretada como a quantidade de risco associada a uma unidade no tempo t e a unidade de medida é normalmente dada em termos de falhas por unidade de tempo.

$$
h(t)=\frac{f(t)}{R(t)}, t \geq 0
$$


onde $\mathrm{h}(\mathrm{t})$ é a função de risco, $\mathrm{f}(\mathrm{t})$ a densidade de probabilidade e $\mathrm{R}(\mathrm{t})$ a função de confiabilidade. A função de confiabilidade $\mathrm{R}(\mathrm{t})$ informa a probabilidade de a unidade apresentar ausência de falhas no intervalo de tempo $(0, \mathrm{t})$ e ainda estar funcionando no tempo t. Dessa forma, o tempo médio até a falha de uma unidade, designado por MTTF (do inglês mean time to failure), pode ser designado como:

$$
M T T F=\int_{0}^{\infty} R(t) d t
$$

onde MTTF é o tempo médio até a falha da unidade e $\mathrm{R}(\mathrm{t})$ a função de confiabilidade.

Alguns modelos para explicar o comportamento de tempos até a falha surgem na literatura: (i) $h(t)$ constante, o modelo exponencial, que explica o comportamento de componentes eletrônicos; (ii) $h(t)$ linear crescente, o modelo de Rayleigh, que explica o comportamento de componentes mecânicos; e (iii) $h(t)$ exponencial, o modelo de Weibull, que explica o comportamento de sistemas cuja falha nasce da competição entre diversos modos de falha atuando em série competindo pela falha, como em equipamentos industriais (SELLITO, 2005).

O modelo de Weibull interessa a três parâmetros: (i) $t_{0}$, que indica o tempo isento de falhas; (ii) $\gamma$, o fator de forma, que indica taxa de falhas decrescente $(\gamma<1)$, constante $(\gamma=1)$ ou crescente $(\gamma>1)$; e (iii) $\theta$, o fator de escala, que indica o quanto a distribuição se espalha no tempo. Um dos métodos difundidos para estimar os parâmetros populacionais é o método da máxima verossimilhança, que para a distribuição de Weibull é obtida iterativamente.

As representações de confiabilidade de Weibull são fornecidas pelas seguintes equações (FOGLIATTO\&DUARTE, 2009).

$$
\begin{gathered}
R(t)=e^{-\left(\frac{t}{\theta}\right)^{\gamma}} \\
h(t)=\frac{\gamma}{\theta}\left(\frac{t}{\theta}\right)^{\gamma-1} \\
M T T F=\theta \Gamma\left(1+\frac{1}{\gamma}\right)
\end{gathered}
$$

onde $\Gamma$ da Equação (3.6) designa a função gama, uma integral indefinida tabelada, $\gamma$ e $\theta$ os parâmetros de forma e escala da Weibull. O tempo médio de reparo (MTTR) determinado pela Equação (3.7) serve como indicativo de tempo para manutenção corretiva, admitindo-se que a falha foi detectada imediatamente e o reparo iniciado em seguida. 


$$
M T T R=\frac{\sum_{i=1}^{n} R_{i}}{n}
$$

onde $\mathrm{R}_{\mathrm{i}}$ é o tempo de reparo da falha i e n o número de falhas.

Os Parâmetros de Weibull podem ser observados na Figura 1 abaixo. Deficiências no processo de manufatura de um produto levam a falhas precoces, que se concentram no início de sua vida, na chamada fase de mortalidade infantil. As falhas que incidem na fase de vida útil do produto devem-se tipicamente a condições extremas no ambiente de operação do produto e podem ocorrer, uniformemente, em qualquer momento no tempo. Finalmente, a deterioração do produto frequentemente leva a falhas por desgaste, concentradas no final da vida útil do produto, na fase de envelhecimento (SELLITO, 2005).

Figura 1 - Curva da banheira e ciclo de vida de equipamentos

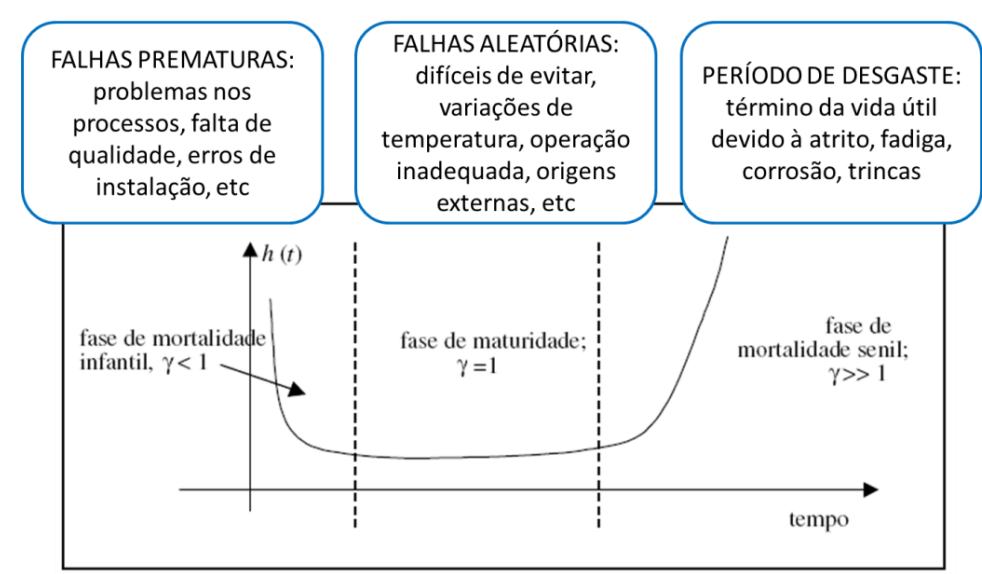

Fonte: Adaptado de SELLITO (2005)

\subsection{FMEA}

A FMEA (Failure Mode and Effects Analysis ou Análise dos Modos de falha) é uma técnica de confiabilidade que tem como objetivos: (i) reconhecer e avaliar as falhas potenciais que podem surgir em um produto ou processo, (ii) identificar ações que possam eliminar ou reduzir a chance de ocorrência dessas falhas, e (iii) documentar o estudo, criando um referencial técnico que possa auxiliar em revisões e desenvolvimentos futuros do projeto ou processo (SELLITO, 2005), apresentando, entre outras, as seguintes vantagens:

- Auxiliar na identificação dos parâmetros do processo a serem controlados para reduzir ou detectar a condição de falha no processo.

- Ajudar na priorização dos modos potenciais de falha, estabelecendo uma ordem para as ações de melhoria no processo;

- Auxiliar na avaliação objetiva de alternativas. 


\subsection{Poka-yokes}

A utilização de princípios e práticas de produção enxuta em empresas de manufatura contribui para garantir a estabilidade da produção, onde os poka-yokes desempenham um papel importante, visto que podem manter sobcontrole anormalidades geradoras de instabilidade (VIDOR, 2010).

Poka-yokes é definido por Vidor e Saurin (2010) como sistemas destinados à detecção de perdas de qualquer natureza sendo constituídos por barreiras físicas e/ou funcionais e/ou simbólicas, que contribuem para a redução da variabilidade e manutenção da estabilidade em processos. As barreiras físicas são aquelas que não permitem o transporte de massas, energia ou informação, bem como não dependem da interpretação do usuário. Barreiras funcionais estabelecem pré-condições que devem ser atendidas antes que um evento ocorra (por exemplo, uma senha), enquanto que barreiras simbólicas requerem interpretação, percepção e resposta do usuário, estando fisicamente presentes nos locais em que são necessários.

\subsubsection{Ajuste e folga de rolamento}

Os rolamentos ao serem assentados com reduzida interferência no eixo e girados com carga no anel interno, podem apresentar entre o anel interno e o eixo um prejudicial movimento relativo na direção circunferencial. Esta ocorrência, denominada deslizamento, pode gerar desgaste na superfície do componente.

Dessa forma, é importante evitar o deslizamento do anel de rolamento que irá girar apoiando a carga durante a operação, fixando-o no eixo ou no alojamento através de uma interferência adequada. A seleção do ajuste é determinada pela direção da carga que incide sobre os rolamentos e das condições de giro dos anéis internos e externos, como apresentado nas Tabelas 3.1 e 3.2. 
Tabela 3.1 - Ajustes dos rolamentos radiais nos eixos

\begin{tabular}{|c|c|c|c|c|c|c|c|}
\hline \multirow{2}{*}{\multicolumn{2}{|c|}{ Condiçāo de Carga }} & \multirow[b]{2}{*}{$\begin{array}{l}\text { Exemplos de } \\
\text { Aplicaçōes } \\
\text { (referencla) }\end{array}$} & \multicolumn{3}{|c|}{ Diametro do Elxo (mm) } & \multirow[b]{2}{*}{$\begin{array}{c}\text { Classe de } \\
\text { Tolerancia do } \\
\text { Elxo }\end{array}$} & \multirow[b]{2}{*}{ Observaçâo } \\
\hline & & & $\begin{array}{c}\text { Rolamentos } \\
\text { de Esferas }\end{array}$ & $\begin{array}{l}\text { Rolamentos } \\
\text { de Rolos } \\
\text { Cillindricose } \\
\text { Conicos } \\
\end{array}$ & \begin{tabular}{|c|} 
Rolamentos Auto- \\
compensadores \\
de rolos
\end{tabular} & & \\
\hline \multicolumn{8}{|c|}{ Rolamentos de Furos Cilíndricos e Eixos } \\
\hline \multirow{2}{*}{$\begin{array}{c}\text { Carga } \\
\text { Rotativa no } \\
\text { Anel Externo }\end{array}$} & $\begin{array}{l}\text { Necessário Mov. o Anel } \\
\text { Interno no Eixo com } \\
\text { Facilidade }\end{array}$ & $\begin{array}{l}\text { Roda com Eixo } \\
\text { Estático }\end{array}$ & \multirow{2}{*}{\multicolumn{3}{|c|}{ Todos os Diâmetros de Eixo }} & g6 & \multirow{2}{*}{$\begin{array}{l}\text { Usar g5 ou h5 } \\
\text { na necessidade } \\
\text { de precisāo. } \\
\text { Nos rols. grandes } \\
\text { pode ser f6 para } \\
\text { facilitar o movimento. }\end{array}$} \\
\hline & $\begin{array}{l}\text { Sem Necessid. de Mov. } \\
\text { o Anel Interno no Eixo } \\
\text { com Facilidade } \\
\end{array}$ & $\begin{array}{l}\text { Polia Tensora, } \\
\text { Roldanas }\end{array}$ & & & & h6 & \\
\hline \multirow{16}{*}{$\begin{array}{c}\text { Carga } \\
\text { Rotativa no } \\
\text { Anel Interno } \\
\text { ou Carga } \\
\text { de Direçāo } \\
\text { Inconstante }\end{array}$} & \multirow{4}{*}{$\begin{array}{l}\text { Carga Leve } \\
\left(<0.06 C_{r}\left({ }^{1}\right)\right) \\
\text { Carga Variável }\end{array}$} & \multirow{4}{*}{$\begin{array}{l}\text { Eletrodomésticos, } \\
\text { Bombas, Ventiladores, } \\
\text { Carrinhos, Máquinas de } \\
\text { Precisão e Operatrizes }\end{array}$} & $<18$ & - & - & Js5 & \multirow{4}{*}{$\begin{array}{l}\text { Classe de tolerância } 5 \text { nos } \\
\text { que requerem precisão, } \\
\text { usar também o rol. de alta } \\
\text { precisāo. Usar } h 5 \text { nos rols. } \\
\text { de esferas de alta precisão } \\
\text { com furo < } 18 \mathrm{~mm} \text {. }\end{array}$} \\
\hline & & & $18 \sim 100$ & $<40$ & - & Js6 (16) & \\
\hline & & & $100 \sim 200$ & $40 \sim 140$ & - & k6 & \\
\hline & & & - & $140 \sim 200$ & - & m6 & \\
\hline & \multirow{8}{*}{$\begin{array}{c}\text { Carga Normal } \\
\left(0.06 \text { a } 0.13 C_{r}\left({ }^{1}\right)\right)\end{array}$} & \multirow{8}{*}{$\begin{array}{l}\text { Motores Elétricos } \\
\text { Médios e Grandes, } \\
\text { Turbinas, Bombas, } \\
\text { Rolamento Principal } \\
\text { de Motores, } \\
\text { Mecanismo de } \\
\text { Transmissão do } \\
\text { Movimento por } \\
\text { Engrenagens, } \\
\text { Máquinas de } \\
\text { Marcenaria } \\
\end{array}$} & $<18$ & - & - & $\mid s 5 \sim 6(\mid 5 \sim 6)$ & \multirow{8}{*}{$\begin{array}{l}\text { Nos rols. de rolos } \\
\text { cônicos e de } \\
\text { esferas de contato } \\
\text { angular, de uma } \\
\text { carreira, pode ser } \\
\text { usado k6 ou m6 no } \\
\text { lugar de k5 ou m5. }\end{array}$} \\
\hline & & & $18 \sim 100$ & $<40$ & $<40$ & $k 5 \sim 6$ & \\
\hline & & & $100 \sim 140$ & $40 \sim 100$ & $40 \sim 65$ & $\mathrm{~m} 5 \sim 6$ & \\
\hline & & & $140 \sim 200$ & $100 \sim 140$ & $65 \sim 100$ & m6 & \\
\hline & & & $200 \sim 280$ & $140 \sim 200$ & $100 \sim 140$ & n6 & \\
\hline & & & - & $200 \sim 400$ & $140 \sim 280$ & p6 & \\
\hline & & & - & - & $280 \sim 500$ & r6 & \\
\hline & & & - & - & Acima de 500 & r7 & \\
\hline & \multirow{4}{*}{$\begin{array}{c}\text { Carga Pesada } \\
\left(>0.13 C_{r}\left({ }^{(1)}\right)\right) \\
\text { Carga de Choque }\end{array}$} & \multirow{4}{*}{\begin{tabular}{|l|} 
Rodeiro Ferroviário, \\
Rodeiro Industrial, \\
Motor de Tração, \\
Máquinas de Construçāo \\
Civil, Britadores \\
\end{tabular}} & - & $50 \sim 140$ & $50 \sim 100$ & n6 & \multirow{4}{*}{$\begin{array}{l}\text { Necessário o } \\
\text { rolamento de } \\
\text { folga maior que o } \\
\text { normal. }\end{array}$} \\
\hline & & & - & $140 \sim 200$ & $100 \sim 140$ & p6 & \\
\hline & & & - & acima de 200 & $140 \sim 200$ & r6 & \\
\hline & & & - & - & $200 \sim 500$ & r7 & \\
\hline \multicolumn{2}{|c|}{ Somente Carga Axial } & & \multicolumn{3}{|c|}{ Todos os Diâmetros de Eixo } & Is6 (i6) & - \\
\hline \multicolumn{8}{|c|}{ Rolamentos de Furo Cônico (com Bucha) e Eixos } \\
\hline \multirow{2}{*}{\multicolumn{2}{|c|}{ Todos os Tipos de Carga }} & $\begin{array}{c}\text { Uso Genérico, } \\
\text { Rodeiro Ferroviário }\end{array}$ & \multirow{2}{*}{\multicolumn{3}{|c|}{ Todos os Diâmetros de Eixo }} & h9/T5 & \multirow{2}{*}{$\begin{array}{l}\text { IT5 e IT7 indicam } \\
\text { as tolerâncias dos } \\
\text { desvios como o } \\
\text { de circularidade e } \\
\text { cilindricidade do } \\
\text { eixo. }\end{array}$} \\
\hline & & \begin{tabular}{|c|}
$\begin{array}{c}\text { Eixos Acionadores, } \\
\text { Máquina de } \\
\text { Marcenaria }\end{array}$ \\
\end{tabular} & & & & h10/T7 & \\
\hline
\end{tabular}

Fonte: NSK 
Tabela 3.2 - Ajustes dos rolamentos radiais nos alojamentos

\begin{tabular}{|c|c|c|c|c|c|c|}
\hline \multicolumn{3}{|c|}{ Condliçẫo de Carga } & $\begin{array}{c}\text { Exemplos de Aplicaçōes } \\
\text { (referência) }\end{array}$ & $\begin{array}{l}\text { Classe de } \\
\text { Tol. do } \\
\text { Alolamento }\end{array}$ & \begin{tabular}{|c|} 
Movimento \\
Axial do Anel \\
Externo
\end{tabular} & Observaçăo \\
\hline \multirow{5}{*}{$\begin{array}{l}\text { Alojamento } \\
\text { Monobloco }\end{array}$} & \multirow{3}{*}{$\begin{array}{c}\text { Carga } \\
\text { Rotativa } \\
\text { no Anel } \\
\text { Externo }\end{array}$} & $\begin{array}{l}\text { Carga Pesada em Aloj. Fino } \\
\text { Carga Pesada de Choque }\end{array}$ & $\begin{array}{l}\text { Roda de Veíc. (Rol. de } \\
\text { Rolos), Roda de Guindaste }\end{array}$ & P7 & \multirow{4}{*}{ Impossivel } & \multirow{4}{*}{ - } \\
\hline & & \begin{tabular}{|l|} 
Carga Normal \\
Carga Pesada
\end{tabular} & \begin{tabular}{|l|} 
Roda de Veíc. (Rol. de \\
Esferas), Peneira Vibratória
\end{tabular} & N7 & & \\
\hline & & \begin{tabular}{|l} 
Carga Leve \\
Carga Variável
\end{tabular} & $\begin{array}{l}\text { Rolete Transportador, Vagão } \\
\text { de Carga, Polia Tensora }\end{array}$ & & & \\
\hline & \multirow{3}{*}{$\begin{array}{l}\text { Carga de } \\
\text { Direção } \\
\text { Incons } \\
\text { tante }\end{array}$} & Carga Pesada de Choque & Motor de Traçāo & & & \\
\hline & & $\begin{array}{l}\text { Carga Normal } \\
\text { Carga Pesada }\end{array}$ & $\begin{array}{l}\text { Bombas, Rol. Principal } \\
\text { do Virabrequim, Motores }\end{array}$ & K7 & $\begin{array}{l}\text { Como } \\
\text { Principio } \\
\text { não se } \\
\text { Movimenta }\end{array}$ & $\begin{array}{l}\text { Casos em que não há } \\
\text { necessidade de movimento } \\
\text { do anel externo na direção } \\
\text { axial. }\end{array}$ \\
\hline \multirow{4}{*}{$\begin{array}{l}\text { Alojamento } \\
\text { Monobloco } \\
\text { ou Bipartido }\end{array}$} & & $\begin{array}{l}\text { Carga Normal } \\
\text { Carga Leve }\end{array}$ & $\begin{array}{l}\text { Elétricos Médios e } \\
\text { Grandes }\end{array}$ & JS7 (JT) & Possivel & $\begin{array}{l}\text { Casos em que há } \\
\text { necessidade de movimento } \\
\text { do anel externo na direção } \\
\text { axial. }\end{array}$ \\
\hline & \multirow{4}{*}{$\begin{array}{l}\text { Carga } \\
\text { Rotativa } \\
\text { no Anel } \\
\text { Interno }\end{array}$} & Todos os Tipos de Carga & $\begin{array}{l}\text { Uso Genérico, Caixa de } \\
\text { Rol. Ferroviário. }\end{array}$ & H7 & \multirow{3}{*}{$\begin{array}{l}\text { Movimenta } \\
\text { com } \\
\text { Facilidade }\end{array}$} & \multirow{3}{*}{ - } \\
\hline & & \begin{tabular}{|l|} 
Carga Normal \\
Carga Leve \\
\end{tabular} & Caixas & $\mathrm{HB}$ & & \\
\hline & & $\begin{array}{l}\text { Alta Temp. no Eixo e } \\
\text { Anel Interno }\end{array}$ & Secador de Papel & G7 & & \\
\hline \multirow{4}{*}{$\begin{array}{l}\text { Alojamento } \\
\text { Monobloco }\end{array}$} & & Requer Especialmente 0 & $\begin{array}{l}\text { Rol. de Esferas Traseiro do } \\
\text { Fuso de Retificadora, Rol. } \\
\text { Lado Livre do Compressor } \\
\text { Centrífugo de Alta Rotação }\end{array}$ & JS6 (J6) & Possivel & - \\
\hline & $\begin{array}{l}\text { Carga de } \\
\text { Direção } \\
\text { Incons- } \\
\text { tante }\end{array}$ & Normais ou Leves & $\begin{array}{l}\text { Rol. de Esferas Dianteiro } \\
\text { do Fuso de Retificadora, } \\
\text { Rol. Lado Fixo do } \\
\text { Compressor Centrífugo de } \\
\text { Alta Rotação }\end{array}$ & K6 & $\begin{array}{l}\text { Como } \\
\text { Princípio não } \\
\text { se Movimenta }\end{array}$ & \multirow{2}{*}{$\begin{array}{l}\text { Ajuste com interf. > } K \\
\text { para cargas pesadas. } \\
\text { Quando requer altas } \\
\text { precisões, usar de acordo } \\
\text { com a aplicação, as } \\
\text { tolerâncias mais estreitas. }\end{array}$} \\
\hline & \multirow{2}{*}{$\begin{array}{l}\text { Carga } \\
\text { Rotativa } \\
\text { no Anel } \\
\text { Interno }\end{array}$} & $\begin{array}{l}\text { Requer Precisāo de Giro e } \\
\text { Rigidez com Carga Variável }\end{array}$ & $\begin{array}{l}\text { Rol. de Rolos Cilind. para } \\
\text { Fusos de Máquinas- } \\
\text { Ferramentas }\end{array}$ & M6 ou N6 & Impossivel & \\
\hline & & $\begin{array}{l}\text { Requer Funcionamento } \\
\text { Silencioso }\end{array}$ & Eletrodomésticos & H6 & $\begin{array}{l}\text { Movimenta } \\
\text { com } \\
\text { Facilidade }\end{array}$ & - \\
\hline
\end{tabular}

Fonte: NSK

\subsubsection{Guias circulares}

As guias modelo HCR da THK consistem em trilhos em formato circunferencial na qual percorrem blocos providos de esferas que rolam em quatro pistas com grau de precisão retificada. Os recirculadores incorporados no bloco permitem a circulação das esferas, como observado na Figura 3.2.

Figura 3.2 - Guia linear da guia R modelo HCR da THK.

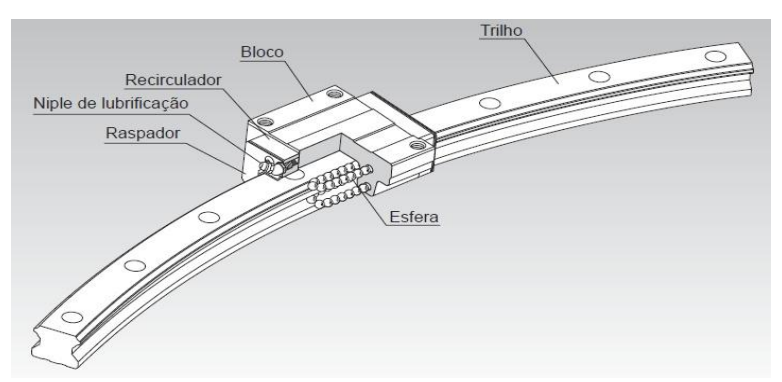

Fonte: THK 


\subsubsection{Lubrificação}

Ao usar um sistema de guias, é necessário fornecer lubrificação eficaz. Sem lubrificação, os elementos de rolagem ou a pista podem se desgastar mais rapidamente e a vida útil pode ser reduzida. Segundo a THK, a lubrificação apresenta funções importantes como minimizar o atrito nos elementos móveis para impedir a gripagem e reduzir o desgaste, formação de um filme de óleo para reduzir tensão que atua sobre a superfície e revestir a superfície metálica para impedir a corrosão.

Com a lubrificação à graxa, os intervalos de lubrificação variam de acordo com as condições e os ambientes. Para uso normal, a THK recomenda lubrificar o sistema aproximadamente a cada $100 \mathrm{~km}$ de distância percorrida. A Tabela 3.3 abaixo auxilia na seleção do lubrificante de acordo coma a aplicação do sistema linear.

Tabela 3.3 - Tabela para seleção de graxa THK.

\begin{tabular}{|c|c|c|c|c|c|c|c|c|}
\hline \multicolumn{2}{|c|}{ Nome do lubrificante } & Graxa AFA & Graxa AFB-LF & Graxa AFC & Graxa AFE-CA & Graxa AFF & Graxa AFG & Graxa AFJ \\
\hline \multicolumn{2}{|c|}{ Características } & $\begin{array}{c}\text { Graxa de baixa } \\
\text { resistência }\end{array}$ & $\begin{array}{c}\text { Graxa } \\
\text { multiuso }\end{array}$ & $\begin{array}{c}\text { Graxa de alta } \\
\text { velocidade/ } \\
\text { microvibração }\end{array}$ & $\begin{array}{c}\text { Graxa para } \\
\text { ambientes } \\
\text { limpos }\end{array}$ & $\begin{array}{c}\text { Graxa para } \\
\text { ambientes } \\
\text { limpos }\end{array}$ & $\begin{array}{c}\text { Graxa para } \\
\text { calor de fuso } \\
\text { de esferas }\end{array}$ & \begin{tabular}{|l|} 
Graxa adequada a \\
uma grande varieda- \\
de de velocidades
\end{tabular} \\
\hline \multicolumn{2}{|c|}{ Óleo de base } & \begin{tabular}{|c|} 
óleo sintético de \\
alta qualidade
\end{tabular} & $\begin{array}{l}\text { óleo mineral } \\
\text { refinado }\end{array}$ & $\begin{array}{c}\text { óleo sintético de } \\
\text { alta qualidade }\end{array}$ & $\begin{array}{c}\text { óleo sintético de } \\
\text { alta qualidade }\end{array}$ & $\begin{array}{c}\text { óleo sintético de } \\
\text { alta qualidade }\end{array}$ & $\begin{array}{c}\text { óleo sintético de } \\
\text { alta qualidade }\end{array}$ & $\begin{array}{c}\text { óleo mineral } \\
\text { refinado }\end{array}$ \\
\hline \multicolumn{2}{|c|}{ Intensificador da consistência } & A base de ureia & A base de lítio & A base de ureia & A base de ureia & A base de lítio & A base de ureia & A base de ureia \\
\hline \multirow{3}{*}{ 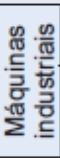 } & \begin{tabular}{|c|} 
Máquinas in- \\
dustriais gerais
\end{tabular} & - & 0 & - & - & - & - & - \\
\hline & Alta velocidade & () & - & - & - & - & () & 0 \\
\hline & $\begin{array}{c}\text { Alta capacida- } \\
\text { de de carga }\end{array}$ & - & 0 & - & - & - & - & - \\
\hline \multirow{4}{*}{ 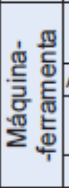 } & $\begin{array}{c}\text { Máquinas-fer- } \\
\text { ramenta gerais }\end{array}$ & - & 0 & - & - & - & - & - \\
\hline & \begin{tabular}{|l|} 
Alta velocidade \\
\end{tabular} & 0 & - & - & - & - & () & 0 \\
\hline & \begin{tabular}{|c|} 
Alta aceleração/ \\
desaceleração
\end{tabular} & 一 & 一 & 一 & 一 & 一 & 一 & 0 \\
\hline & Microvibração & - & - & (1) & - & - & - & - \\
\hline \multirow{5}{*}{ 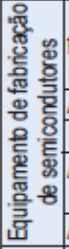 } & \begin{tabular}{|l|} 
Equipamento de \\
fabricação de se- \\
micondutor geral
\end{tabular} & - & 0 & - & - & - & - & - \\
\hline & Alta velocidade & (9) & - & - & - & - & 0 & 0 \\
\hline & Microvibração & - & - & () & - & 0 & - & - \\
\hline & \begin{tabular}{|l|} 
Alta aceleraçãaol \\
desaceleração \\
\end{tabular} & - & - & - & - & - & - & 0 \\
\hline & Ambientes limpos & - & - & - & (1) & (1) & - & - \\
\hline \multirow{4}{*}{ 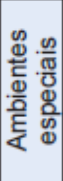 } & Baixa resistência & () & - & - & - & - & 0 & 0 \\
\hline & Baixa geracäo de calor & - & - & - & - & - & (1) & - \\
\hline & $\begin{array}{c}\text { Ampla faixa de } \\
\text { velocidades }\end{array}$ & - & - & - & - & - & - & 0 \\
\hline & \begin{tabular}{|c|}
$\begin{array}{c}\text { Ampla faixa de } \\
\text { temperaturas }\end{array}$ \\
\end{tabular} & - & 一 & 0 & 一 & 一 & - & - \\
\hline \multirow{2}{*}{\multicolumn{2}{|c|}{\begin{tabular}{|l|} 
Cor do pacote decorativo \\
Página de referência
\end{tabular}}} & Verde & Laranja & Azul-escuro & Verde-limão & Azul-claro & Azul & Amarelo \\
\hline & & ब24-7 & D24-8 & ब24-10 & ब24-12 & ब24-14 & ब24-18 & D24-20 \\
\hline
\end{tabular}

Fonte: THK (2012)

\subsubsection{Cálculo da vida útil}

A vida útil de uma guia linear está sujeita a variações mesmo sob as mesmas condições operacionais. Dessa forma, é necessário usar a vida nominal definida abaixo (Equação 3.8) como um valor de referência para a obtenção da vida útil da guia linear (THK, 2012). Para a THK, a vida nominal significa a distância percorrida total que $90 \%$ de um grupo de unidades do mesmo modelo 
de guia linear pode alcançar sem escamação (fragmentos em forma de escamas na superfície metálica) após a operação individual sob as mesmas condições. Para cálculo da vida útil de referencia, são utilizados os fatores fornecidos na Tabela 3.4 que levam em consideração fatores de rigidez, temperatura, contato e carga que tem influencia direta na capacidade de trabalho das guias.

$$
L=\left(\frac{f_{h} f_{t} f_{c}}{f_{w}} \cdot \frac{C}{P_{c}}\right)^{3} .50
$$

onde L é a Vida nominal $(\mathrm{km}), \mathrm{C}$ a Carga nominal dinâmica $(\mathrm{N}), \mathrm{P}_{\mathrm{c}}$ a Carga calculada $(\mathrm{N}), \mathrm{f}_{\mathrm{h}} \mathrm{o}$ fator de rigidez, $f_{t}$ o fator de temperatura, $f_{c}$ ofator de contato e $f_{w} o$ fator de carga.

Tabela 3Erro! Nenhum texto com o estilo especificado foi encontrado no documento..4 - Fatores para o cálculo da vida útil

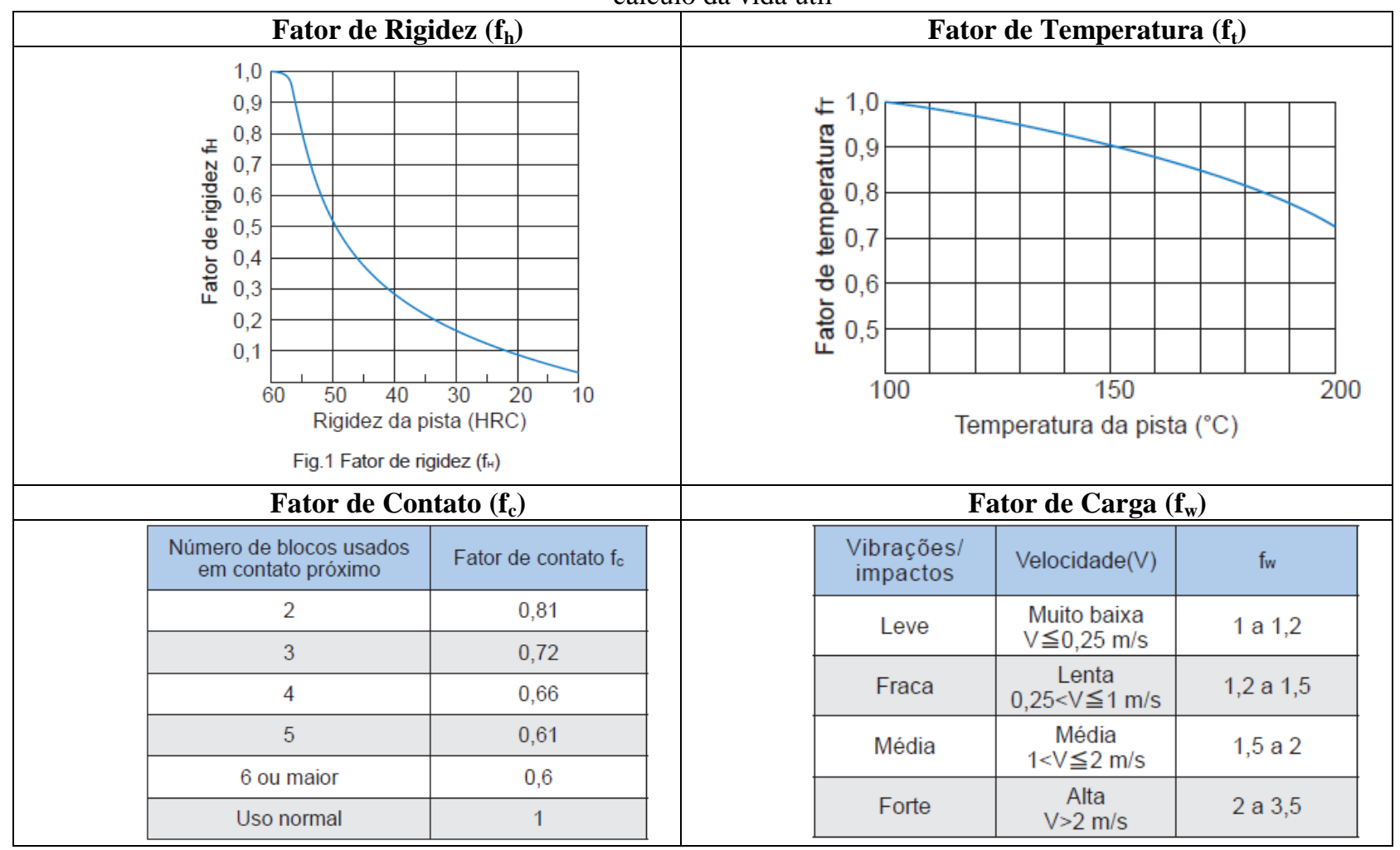

Fonte: THK

\section{Estudo de caso: conjunto desacelerador de produtos}

O módulo de desaceleração de produtos consiste em um conjunto integrante de uma máquina de produtos de higiene, cuja função durante o processo de fabricação é a transferência de produtos de um tambor para outro a uma velocidade de 1500 produtos por minuto, representando uma rotação de 187,5 RPM no sentido anti-horário. O módulo contém oito sapatas que transportam os produtos no processo produtivo com o objetivo de desacelerar o produto fazendo com que ocorra a redução na distância entre produtos, como pode ser observado na Figura 4.1. 
Figura 4.1 - Visualização geral do conjunto desacelerador de produtos

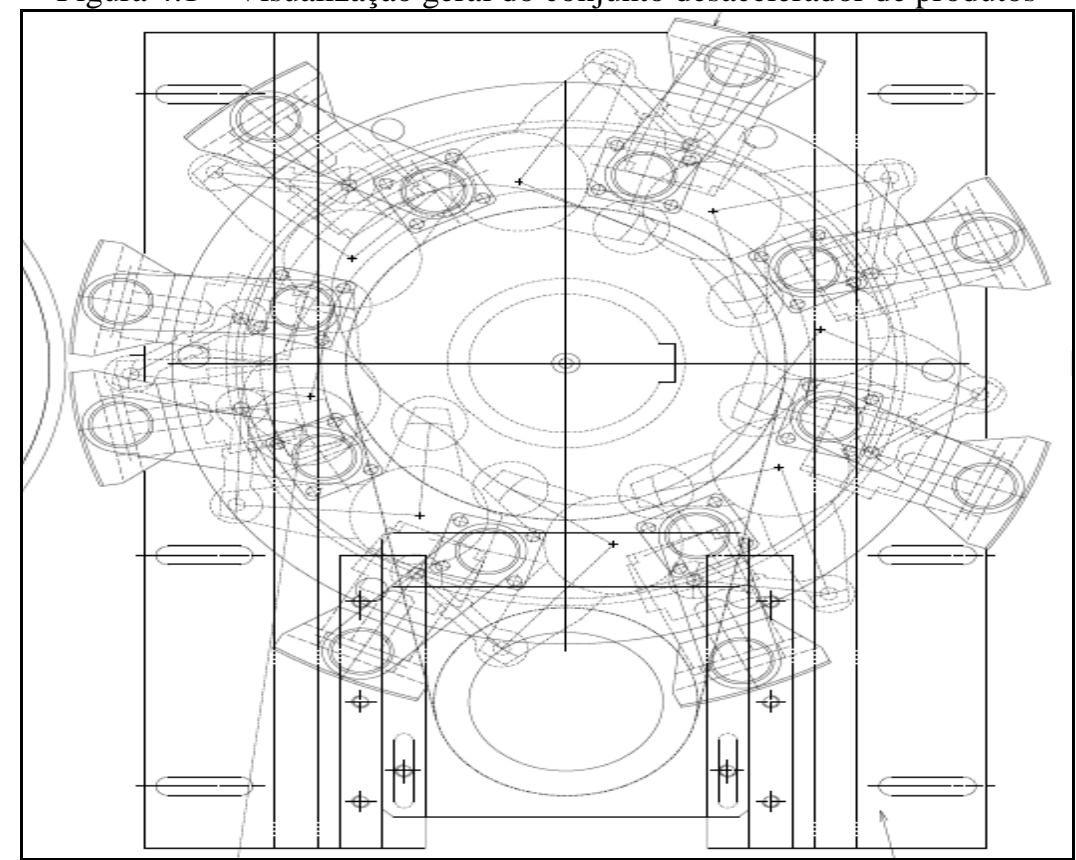

Fonte: Manual do Fabricante

A máquina teve o início de produção em dezembro de 2011 e desde então apresentou frequentes quebras no conjunto desacelerador de produtos. A partir de maio de 2012, o conjunto sofreu modificações de projeto propostas pelo fabricante da máquina para reduzir as falhas mecânicas que contemplavam os eixos, rolamentos e guias circulares. As modificações realizadas no conjunto foram:

- Alteração do perfil do came com redução de $40 \%$ nos esforços transmitidos;

- Aumento do diâmetro do eixo de 17 para $20 \mathrm{~mm}$;

- Redução dos rasgos de chaveta e retirada do anel elástico no eixo;

- Modificações nos mancais para atender o aumento do diâmetro do eixo.

As modificações reduziram as manutenções corretivas, porém ainda ocorreram falhas dos componentes, trazendo perdas de produtividade e custos de manutenção. A manutenção corretiva pode apresentar um custo de $\mathrm{R} \$ 22.500,00$ quando ocorre a danificação das guias circulares e eixos. Caso ocorra a falha do came devido à quebra dos outros componentes (Figura 4.2 (a)), este custo pode chegar a $\mathrm{R} \$ 37.500,00$.

A Figura 4.2 apresenta algumas imagens das falhas nos componentes mais frequentes ocorridas, sendo 1 e 2 ocorrido mesmo após as modificações do fabricante citadas acima. 
Figura 3.2 - Imagens de algumas falhas no equipamento, em (a) travamento dos rolamentos no came após quebra da guia circular, em (b) oxidação dos trilhos devido à lubrificação insuficiente e em (c) ruptura dos eixos

(a)

(c)

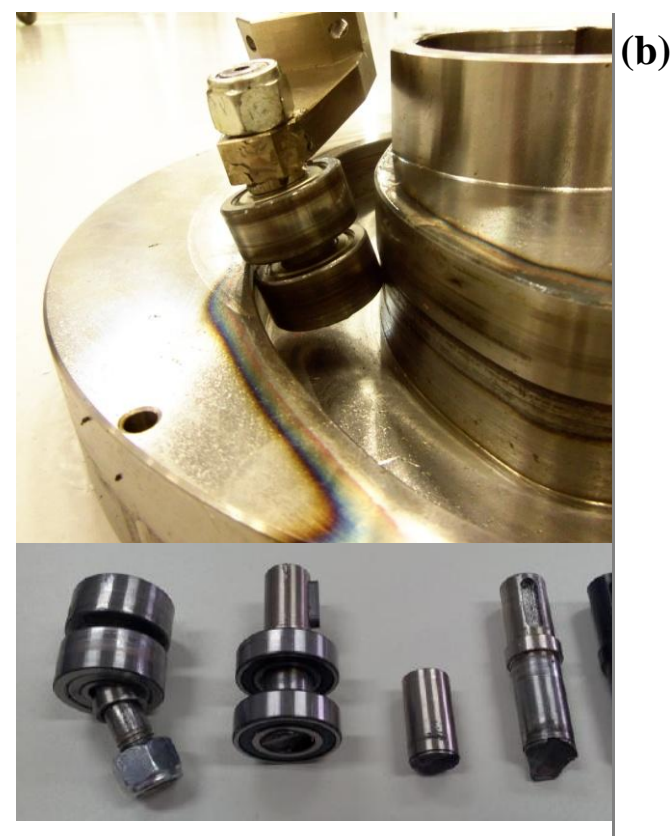

Fonte: Fotos do autor

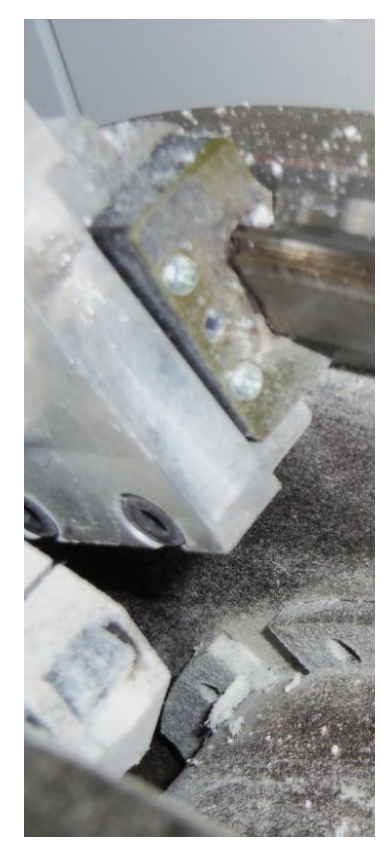

\section{Metodologia}

A metodologia utilizada para aumentar a disponibilidade da máquina é baseada na MCC apoiada na análise das falhas, uso da metodologia FMEA e implementação das melhorias analisadas para reduzir a possibilidade de ocorrência de falhas e garantir que o equipamento execute suas funções a custos mínimos.

\subsection{Histórico de falhas do equipamento}

Desde o start-up da máquina em dezembro de 2011 até junho de 2012, o módulo desacelerador de produtos teve os tempos entre falhas em horas apresentados na Tabela 5.1 e tempos de reparos apresentados na Tabela 5.2.

Tabela 5.1 - Tempo entre falhas (h)

\begin{tabular}{|c|c|c|c|c|c|c|c|c|c|}
\hline 13 & 52 & 74 & 22 & 6 & 3 & 11 & 6 & 48 & 2 \\
\hline 14 & 10 & 24 & 48 & 4 & 123 & 188 & 51 & 60 & 54 \\
\hline 162 & 34 & 64 & 2 & 17 & 25 & 37 & 19 & 42 & 25 \\
\hline 5 & 18 & 9 & 19 & 1 & 17 & 28 & 601 & 121 & 102 \\
\hline 28 & 11 & 4 & 8 & 169 & 66 & 4 & 89 & 167 & 281 \\
\hline 23 & \multicolumn{9}{|c|}{}
\end{tabular}

Fonte: Histórico do equipamento

Tabela 5.2 - Tempos de reparo (h:min)

\begin{tabular}{|l|c|c|c|c|c|c|c|c|c|}
\hline $2: 36$ & $4: 00$ & $1: 37$ & $2: 48$ & $2: 00$ & $0: 33$ & $0: 32$ & $8: 04$ & $1: 31$ & $1: 00$ \\
\hline $1: 16$ & $1: 25$ & $1: 14$ & $1: 04$ & $1: 00$ & $5: 56$ & $0: 58$ & $1: 00$ & $1: 40$ & $1: 46$ \\
\hline $2: 00$ & $0: 54$ & $1: 26$ & $1: 00$ & $0: 08$ & $0: 30$ & $1: 00$ & $1: 00$ & $0: 26$ & $0: 30$ \\
\hline $5: 21$ & $2: 18$ & $2: 00$ & $0: 20$ & $2: 00$ & - & $1: 30$ & $3: 30$ & - & $0: 26$ \\
\hline $7: 08$ & $0: 36$ & $5: 03$ & $0: 37$ & $0: 07$ & $1: 04$ & $0: 50$ & $0: 42$ & - & $0: 53$ \\
\hline $1: 13$ & \multicolumn{9}{|c|}{} \\
\hline
\end{tabular}

Fonte: Histórico do equipamento 


\subsection{Medidas de confiabilidade}

Foi utilizado o programa ProConf 2000 para obtenção dos gráficos de função de confiabilidade $\mathrm{R}(\mathrm{t})$ e taxa de falha $\mathrm{h}(\mathrm{t})$ apresentados na Figura 5.1, além de testar o ajuste dos dados às distribuições exponencial, Weibull, gamma, normal e lognormal As análises estatísticas que demonstram que a hipótese de que a população segue o modelo de distribuição de Weibull não pode ser rejeitada, assim os gráficos $\mathrm{R}(\mathrm{t})$ e $\mathrm{h}(\mathrm{t})$ são baseados nas Equações (3.4) e (3.5). O MTTF resultante (Equação (3.5)) resultou em $\mathrm{MTTF}_{1}=57,7$ horas com $\gamma_{1}=0,76$ indicando que o módulo apresenta-se na fase de mortalidade infantil. Com o tempo médio de reparo $\mathrm{MTTR}_{1}=1,83$ horas para os dados apresentados, a disponibilidade do equipamento (Equação 5.1) é dado por:

$$
A_{1}=\frac{M T T F}{M T T F+M T T R}=\frac{57,7}{57,7+1,83}=96,9 \%
$$

Figura 4.1 - Representação da taxa de falhas (E) e confiabilidade (D) do equipamento.

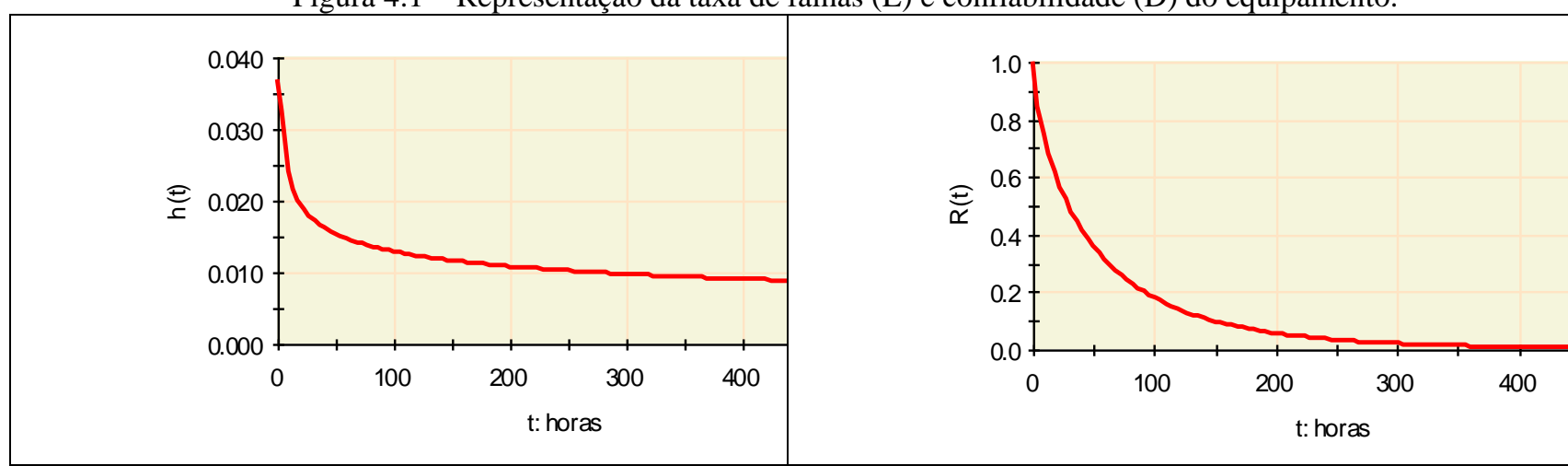

Fonte: Resultado do programa ProConf 2000

\subsection{FMEA}

$\mathrm{Na}$ Tabela 5.3 abaixo, são apresentadas as ações obtidas através do FMEA, onde foram analisados os principais modos de falha do conjunto e atribuídas às notas para priorização, sendo os primeiros itens da tabela as prioridades de execução. Os custos de implementação das ações foram estimados através de orçamentos com os fornecedores.

Tabela 5.3 - Ações geradas na análise dos modos de falha

\begin{tabular}{|c|c|c|c|c|}
\hline$\overline{\text { O quê }}$ & Por quê & Como & Onde & Quanto \\
\hline $\begin{array}{l}\text { Criar Plano de } \\
\text { lubrificação }\end{array}$ & $\begin{array}{l}\text { Desgaste das guias } \\
\text { circulares devido a } \\
\text { lubrificação } \\
\text { inadequada }\end{array}$ & $\begin{array}{l}\text { Consultando manual do } \\
\text { fabricante e calculando } \\
\text { condições de trabalho }\end{array}$ & $\begin{array}{l}\text { Manutenção } \\
\text { Mecânica }\end{array}$ & $\begin{array}{c}\mathrm{R} \$ 250,00- \\
\text { Implementação } \mathrm{R} \$ 80,00 \\
- \text { Custo mensal }\end{array}$ \\
\hline $\begin{array}{l}\text { Determinar vida } \\
\text { útil das guias } \\
\text { circulares }\end{array}$ & $\begin{array}{l}\text { Utilizar peça até o } \\
\text { fim de vida para } \\
\text { redução de custo }\end{array}$ & $\begin{array}{c}\text { Calculando parâmetros } \\
\text { do fabricante }\end{array}$ & $\begin{array}{l}\text { Manutenção } \\
\text { Mecânica }\end{array}$ & $\mathrm{R} \$ 0,00$ \\
\hline $\begin{array}{l}\text { Instalar sensor para } \\
\text { detectar } \\
\text { embolamentos de } \\
\text { matéria-prima }\end{array}$ & $\begin{array}{l}\text { Embolamento causa } \\
\text { a quebra das guias } \\
\text { eixos e rolamentos }\end{array}$ & $\begin{array}{c}\text { Instalar sensor em } \\
\text { posição adequada para } \\
\text { detectar rompimento de } \\
\text { matéria-prima }\end{array}$ & $\begin{array}{l}\text { Manutenção } \\
\text { eletrônica }\end{array}$ & $\mathrm{R} \$ 65,00$ \\
\hline
\end{tabular}




\begin{tabular}{|c|c|c|c|c|}
\hline $\begin{array}{c}\text { Verificar } \\
\text { dimensões e } \\
\text { tolerância de eixos } \\
\text { e mancais }\end{array}$ & $\begin{array}{c}\text { Desgaste de eixos e } \\
\text { mancais }\end{array}$ & $\begin{array}{l}\text { Consultando tolerâncias } \\
\text { recomendados pelo } \\
\text { fabricante do rolamento }\end{array}$ & $\begin{array}{c}\text { Manutenção } \\
\text { Mecânica }\end{array}$ & $\mathrm{R} \$ 5700,00$ \\
\hline $\begin{array}{l}\text { Criar Instrução de } \\
\text { Trabalho pra } \\
\text { substituição das } \\
\text { guias circulares }\end{array}$ & $\begin{array}{l}\text { Desalinhamento dos } \\
\text { trilhos acelera } \\
\text { desgaste dos blocos }\end{array}$ & $\begin{array}{l}\text { Ilustrar na Instrução de } \\
\text { Trabalho os passos de } \\
\text { execução e cuidados } \\
\text { necessários }\end{array}$ & $\begin{array}{l}\text { Manutenção } \\
\text { Mecânica }\end{array}$ & $\mathrm{R} \$ 0,00$ \\
\hline $\begin{array}{l}\text { Criar alarme para } \\
\text { lubrificação das } \\
\text { guias conforme } \\
\text { plano de } \\
\text { lubrificação (horas } \\
\text { de trabalho) }\end{array}$ & $\begin{array}{c}\text { Reduzir ao máximo } \\
\text { as interrupções da } \\
\text { máquina }\end{array}$ & $\begin{array}{l}\text { Instalar alarme no } \\
\text { sistema eletrônico do } \\
\text { equipamento }\end{array}$ & $\begin{array}{c}\text { Manutenção } \\
\text { eletrônica }\end{array}$ & $\mathrm{R} \$ 0,00$ \\
\hline
\end{tabular}

\subsection{Implementação de melhorias e da manutenção preventiva}

Com as análises estatísticas de falhas e ações geradas pelo FMEA foram implementadas melhorias no equipamento e a estratégia de manutenção adequada a cada item com relação ao seu respectivo modo de falha, encaminhando para atividades preditivas ou preventivas.

\subsubsection{Ajuste e folga de rolamento}

Avaliando as cargas atuantes e baseando-se nas Figuras 9.1 e 9.2 do fabricante de rolamentos, para uma carga normal rotativa no anel interno para um rolamento de esferas de 18 a 100 mm de diâmetro de eixo tem-se indicado uma classe de tolerância no eixo k5, ou seja, ajuste com interferência. Essa indicação de tolerância difere do fabricante da máquina, que classifica com ajuste incerto com h7 de tolerância no eixo.

Para ajuste do rolamento no alojamento para carga rotativa no anel interno. a classe de tolerância no alojamento indicado é H7, ou seja, ajuste com fácil movimentação. Neste aspecto, também há divergência com relação ao fabricante da máquina que sugere ajuste incerto com classe de tolerância J6. Dessa forma, os desenhos foram revisados com a nova proposta de classe de tolerância.

\subsubsection{Plano de lubrificação}

Para implementar o plano de lubrificação, é necessário determinar a distância percorrida pelas guias circulares. Para isso, foi realizada uma simulação através do programa Working Model para determinação do perfil de velocidade obtido por influência do came. No programa foi inserido as dimensões apresentadas na Figura 5.2 obtidas de medições realizadas no came.

Figura 5.2 - Medidas obtidas para o raio do came 


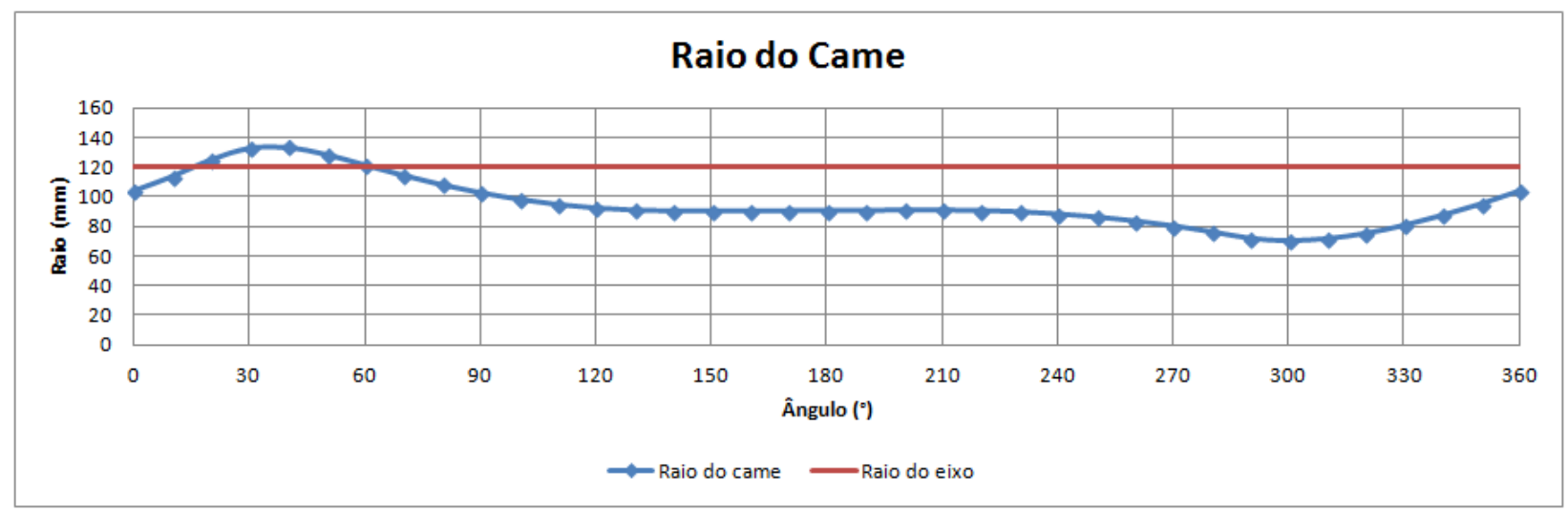

Fonte: Resultado do programa Working Model

A velocidade de rotação do conjunto é 187,5 rpm para a velocidade máxima de produção da máquina. Como a velocidade linear é diretamente proporcional à velocidade angular e o software exporta medidas a cada $0,025 \mathrm{~s}$, foi realizada a simulação com velocidade de rotação de $30 \mathrm{rpm}$ para obtenção de dados mais consistentes. A Figura 5.3 apresenta o perfil de velocidade linear $\mathrm{V}_{\mathrm{g}}$ da guia circular no período de 2 segundos.

Figura 5.3 - Perfil de velocidade do trilho e da guia circular para 30rpm

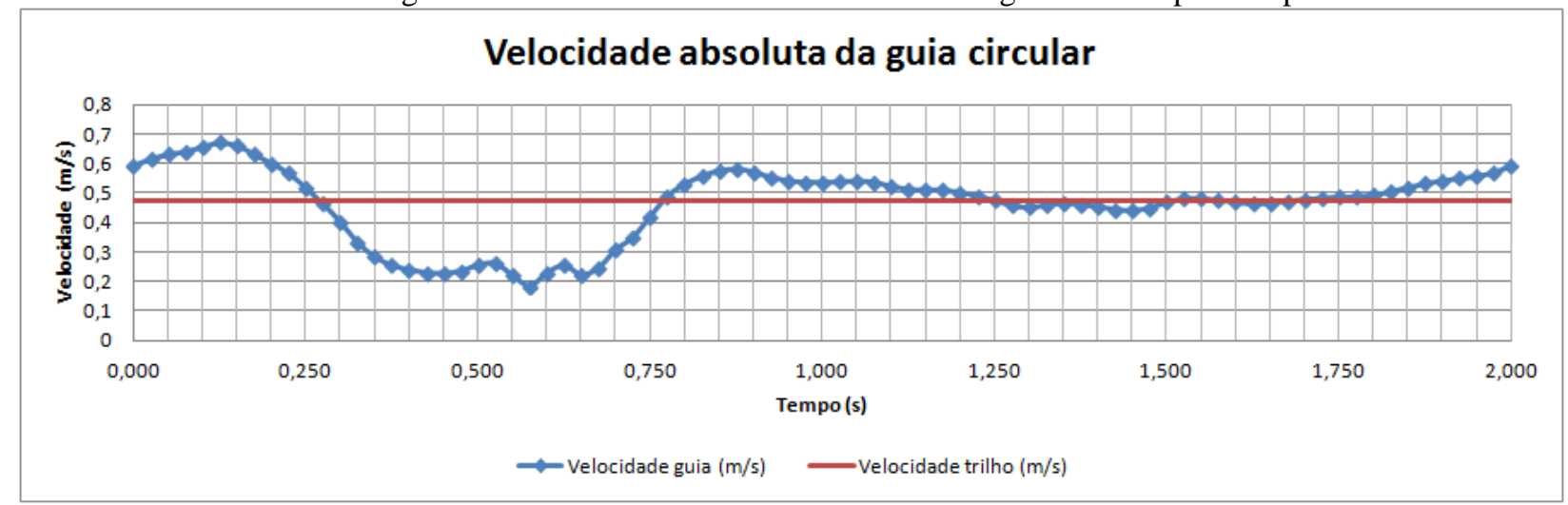

Fonte: Resultado do programa Working Model

O trilho das guias circulares é fixado na base do conjunto rotativo, ou seja, também se encontram em rotação em um raio de $150 \mathrm{~mm}$. Portanto, a velocidade dos trilhos $\mathrm{V}_{\mathrm{t}}$, dada pelo produto do raio do trilho pela velocidade angular do conjunto, é $0,471 \mathrm{~m} / \mathrm{s}$. Subtraindo-se a velocidade das guias pela velocidade constante dos trilhos, temos as velocidades das guias relativas aos trilhos representado na Figura 5.4 abaixo. 
Figura Erro! Nenhum texto com o estilo especificado foi encontrado no documento.5.4 - Perfil de velocidade da guia circular relativa ao trilho para $30 \mathrm{rpm}$

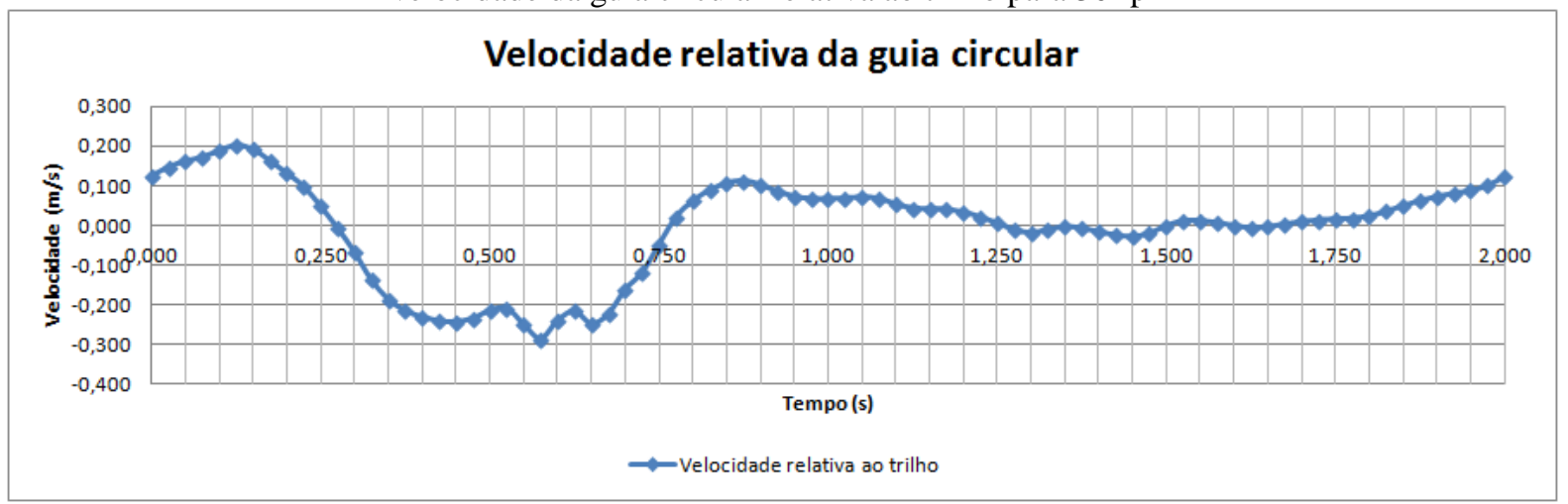

Fonte: Resultado do programa Working Model

Para obter a distância percorrida pela guia por rotação do conjunto, foi utilizada a fórmula geral de aproximação da integral pela regra dos trapézios (Equação 5.2).

$$
\int_{0}^{s} d s=\int_{0}^{t} v d t \approx t\left(\frac{v_{0}}{2}+v_{1}+v_{2}+v_{3}+\ldots+v_{n-1}+\frac{v_{n}}{2}\right)
$$

Onde S é distância percorrida pelos blocos da guia circular, v a velocidade do bloco em relação ao trilho no instante de tempo t.

Da integração numérica dos 81 dados de velocidade temos a distância percorrida em uma rotação (Equação 5.3):

$$
\int_{0}^{s} d s=\int_{0}^{2}\left|v_{g}(t)\right| d t \approx 0,18 m
$$

Assim, através da equação 5.4 temos as horas trabalhadas T para uma distância de $100 \mathrm{~km}$ percorridos e velocidade angular de 187,5rpm.

$$
T=1 /\left(\frac{1}{100000 m} \cdot \frac{0,18 m}{\text { rotação }} \cdot \frac{187,5 \text { rotações }}{\min } \cdot \frac{60 \mathrm{~min}}{1 \text { hora }}\right)=49,4 \text { horas }
$$

Utilizando uma estimativa de tempo de máquina rodando de $65 \%$ o tempo de relubrificação proposto foi de 65,9 horas.

A velocidade máxima do bloco em relação à guia que resultou na simulação foi de $\mathrm{V}_{\mathrm{g}}=$ $0,20 \mathrm{~m} / \mathrm{s}$, como apresentado na figura 5.5. Sendo a velocidade de trabalho de $187,5 \mathrm{rpm}$, a velocidade máxima $\mathrm{V}_{\text {gmáx }}$ será (Equação):

$$
V_{\text {gmáx }}=\frac{187,5 \mathrm{rpm}}{30 \mathrm{rpm}} \cdot 0,20 \mathrm{~m} / \mathrm{s}=1,25 \mathrm{~m} / \mathrm{s}
$$


Esta velocidade é classificada como média conforme Tabela 3.2 e lubrificante utilizado foi o AFA da THK à base de ureia e óleo sintético indicado para altas velocidades, com periodicidade de relubrificação a cada 65 horas.

Para evitar as estimativas de tempo de relubrificação causado pelo tempo de máquina rodando que podem tornar a lubrificação desnecessária ou insuficiente foi criado o sistema de mensagem para lubrificação que consiste em uma mensagem no display da máquina após 48,8 horas de máquina em funcionamento que será mostrada de 20 em 20 minutos até que a lubrificação seja realizada. Após a lubrificação, os técnicos mecânicos realizam o reset de contagem utilizando uma senha, iniciando novamente a contagem de tempo até a próxima lubrificação. Esta metodologia de controle da lubrificação pode ser entendida como um Poka-yoke, pois atua como uma barreia funcional que contribui para reduzir a variabilidade, reduzindo interpretações e percepções do usuário.

\subsubsection{Determinação da vida útil}

Para determinar a vida útil da guia circular, é necessária a carga aplicada. Uma simulação em um estudo realizado pela Engenharia Corporativa da companhia nos Estados Unidos verificou que o came recebe um pico de tensão no ponto em que o came atinge seu raio máximo, variando de valores próximos de $200 \mathrm{~N}$ até seu máximo $\mathrm{F}_{\mathrm{r}}=2376 \mathrm{~N}$. Para este ponto, a carga atuante no boco da guia circular é $\mathrm{F}_{\mathrm{g}}=646 \mathrm{~N}$, como apresentado na Figura 5.5.

Figura 5.5 - Força resultante na guia circular

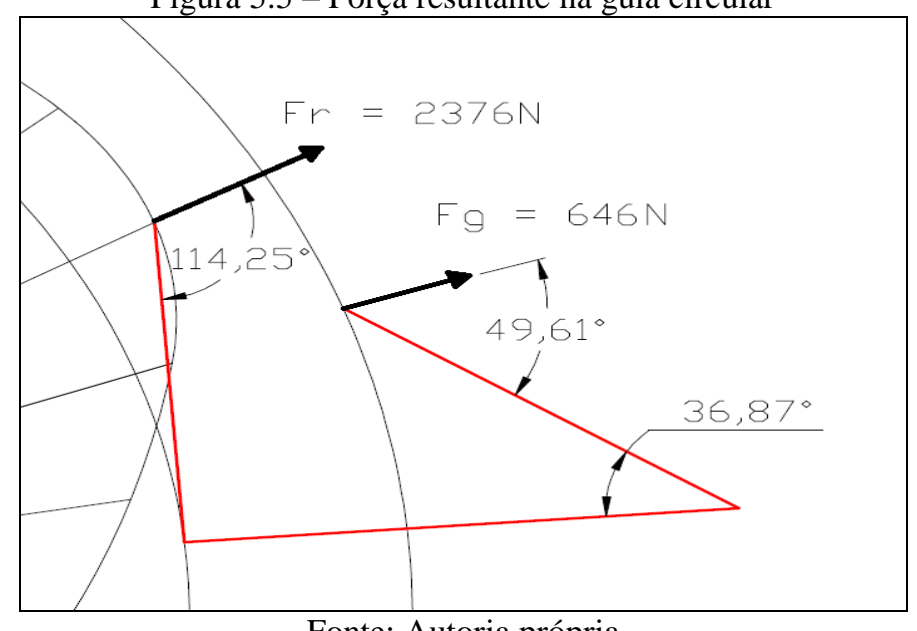

Fonte: Autoria própria

Assim, considerando os fatores de dureza, temperatura e contato igual a 1 e o fator de carga igual a 1,5 para uma classificação de velocidade média, temos na Equação 5.6 uma vida útil calculada de $7121 \mathrm{~km}$.

$$
L=\left(\frac{f_{h} f_{t} f_{c}}{f_{w}} \cdot \frac{C}{P_{c}}\right)^{3} \cdot 50=\left(\frac{1 \cdot 1 \cdot 1}{1,5} \cdot \frac{4,7}{0,6}\right)^{3} \cdot 50=7121 \mathrm{~km}
$$


Dessa forma, tendo como referência o tempo necessário para percorrer $100 \mathrm{~km}$, a vida estimada em dias obtida como referência é de 146 dias (Equação 5.7).

$$
T_{\text {vida }}=\frac{49,4 \text { horas }}{100 \mathrm{~km}} \cdot 7121 \mathrm{~km} \cdot \frac{1 \text { dia }}{24 \text { horas }}=146 \text { dias }
$$

\subsubsection{Instrução de trabalho para substituição das guias circulares}

A base de um trabalho de um programa de MCC é a definição das funções e padrões, dessa forma foi criada uma instrução de trabalho para substituição das guias circulares devido a sua criticidade para o equipamento de forma manter a confiabilidade no desempenho do equipamento. A seguir encontra-se a instrução de trabalho na qual os técnicos de manutenção foram treinados para execução do serviço.

\begin{tabular}{|c|c|c|c|c|}
\hline \multicolumn{5}{|c|}{ INSTRUÇÃO DE TRABALHO } \\
\hline \multicolumn{2}{|c|}{ REVISÃO: 00} & \multicolumn{3}{|c|}{ DATA: $\quad 23 / 08 / 2012$} \\
\hline \multicolumn{5}{|c|}{ TÍTULO/OBJETIVO: Substituição das Guias Circulares do Conjunto Desacelerador de Produtos } \\
\hline \multicolumn{5}{|c|}{$\begin{array}{l}\text { O objetivo desta instrução de trabalho é padronizar e orientar a substituição das guias circulares do Conjunto } \\
\text { Desacelerador de Produtos. IMPORTANTE: quando um dos rolamentos é danificado, é necessário substituir todo o } \\
\text { conjunto de guias e trilhos. }\end{array}$} \\
\hline \multicolumn{5}{|c|}{ FERRAMENTAS NECESSÁRIAS: Chaves Allen, chaves de boca 8 e 13 , chave de fenda } \\
\hline ILUSTRAÇÃO & COMO EXECUTAR & $\begin{array}{l}\text { PERIGO / } \\
\text { RISCO }\end{array}$ & $\begin{array}{c}\text { MEDIDAS } \\
\text { DE } \\
\text { CONTROLE } \\
\text { / EPIs } \\
\end{array}$ & $\begin{array}{c}\text { EXECUTANT } \\
\mathbf{E}\end{array}$ \\
\hline & $\begin{array}{l}1 \text { - Soltar os terminais } \\
\text { rotulares das sapatas do } \\
\text { conjunto. }\end{array}$ & $\begin{array}{l}\text { Prensar e cortar } \\
\text { as mãos. }\end{array}$ & Utilizar luva & $\begin{array}{l}\text { Técnico } \\
\text { Mecânico }\end{array}$ \\
\hline & $\begin{array}{l}\text { Soltar a sapata } \\
\text { da guia circular }\end{array}$ & $\begin{array}{l}\text { Prensar e cortar } \\
\text { as mãos. }\end{array}$ & Utilizar luva & $\begin{array}{l}\text { Técnico } \\
\text { Mecânico }\end{array}$ \\
\hline$=$ & $\begin{array}{l}2 . \quad \text { Retirar o trilho } \\
\text { com as guias circulares } \\
\text { circular correspondente. } \\
\text { OBS: Sendo } 6 \text { trilhos e } 8 \\
\text { guias, dois trilhos } \\
\text { deverão ser retirados } \\
\text { com duas guias cada. }\end{array}$ & $\begin{array}{l}\text { Prensar e cortar } \\
\text { as mãos. }\end{array}$ & Utilizar luva & $\begin{array}{l}\text { Técnico } \\
\text { Mecânico }\end{array}$ \\
\hline
\end{tabular}




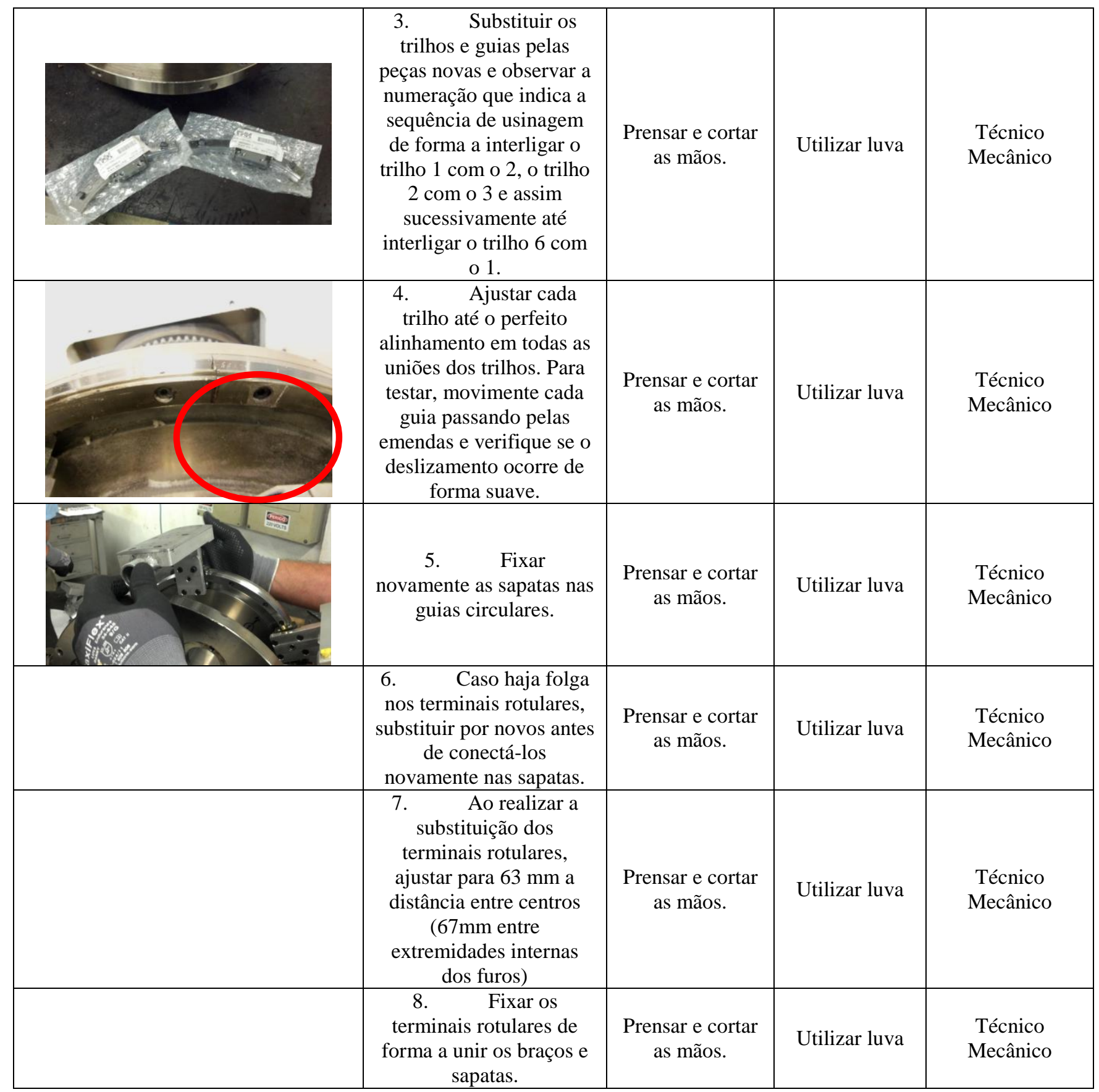

\section{Resultados e discussão}

A determinação da vida útil das guias circulares de 146 dias serve como referência para o desgaste do componente, sendo que falhas com tempo muito menor que a expectativa sugere problemas de lubrificação, operação ou de outras naturezas que precisam ser eliminadas. Dessa forma, considerando que a falha das guias circulares pode gerar falha em todos os outros componentes do conjunto, inclusive no came que tem custo elevado, é indicado criar um plano de manutenção preventiva para substituição das guias baseado no tempo estimado de 146 dias. Aliado a isso, sendo o plano de lubrificação executado manualmente, deve-se inspecionar atentamente as guias de forma a detectar qualquer tipo de anomalia. Os eixos e mancais devem passar por modificação na fabricação de forma a alterar as classes de tolerância, sendo o eixo de $20 \mathrm{~h} 7$ para 
20k5 para gerar ajuste interferente com o rolamento devido a carga rotativa no anel interno, assim como modificação da classe de tolerância de 37J6 para 37H7 permitindo o movimento do rolamento com o mancal. Atualmente, os eixos apresentam desgaste na sede dos rolamentos, ou seja, já é possível perceber em uma inspeção folgas nos componentes que podem favorecer falhas em outros componentes do módulo, que devem ser amenizadas com a substituição dos eixos e mancais com a atualização dos ajustes no eixo e alojamento.

A criação de uma instrução de trabalho auxilia favoravelmente na confiabilidade, pois garante que todos os técnicos de manutenção executem a manutenção utilizando as mesmas técnicas, garantindo que não haverá outros fatores que podem comprometer o desempenho do equipamento. A instrução de trabalho encontra-se disponível para todos funcionários da empresa, além da realização de treinamento para técnicos mecânicos, tornando-os habilitados para execução do serviço.

O estudo e implementação das ações apresentam um custo de $\mathrm{R} \$ 6.015,00$, custo inferior aos R\$ 37.500,00, que pode apresentar uma única manutenção corretiva quando ocorre a danificação das guias circulares, eixos e came. Além disso, às 100 horas acumuladas de manutenção corretiva antes da implementação das melhorias corresponde a um custo de máquina improdutiva de aproximadamente $\mathrm{R} \$ 100.000,00$ além de outras perdas relacionadas como por exemplo perda de velocidade. Isso também serve de argumento para mostrar que torna-se vantajoso as paradas de máquina para lubrificação do equipamento que geram no máximo 60min de indisponibilidade de máquina mensalmente, sem levar em consideração as lubrificações realizadas em oportunidades na qual a máquina não esteja em produção. Além disso, a lubrificação programada aborda uma inspeção em todas as guias, fator que colabora para o aumento da disponibilidade e confiabilidade do equipamento.

Após a implementação do plano de lubrificação nas guias circulares as falhas diminuíram, como se pode observar na Figura 6.1. Do dia 01 de julho até o dia 15 de novembro foram 137 dias de funcionamento do equipamento com a ocorrência de três manutenções corretivas, modificando o $\mathrm{MTTF}_{1}=57,7$ horas para $\mathrm{MTTF}_{2}=1774,0$ horas e $\gamma_{1}=0,76$ para $\gamma_{2}=1,02$ obtido pela análise estatística através do software ProConf. 
Figura 6.1 - Redução da manutenção corretiva após início da lubrificação programada

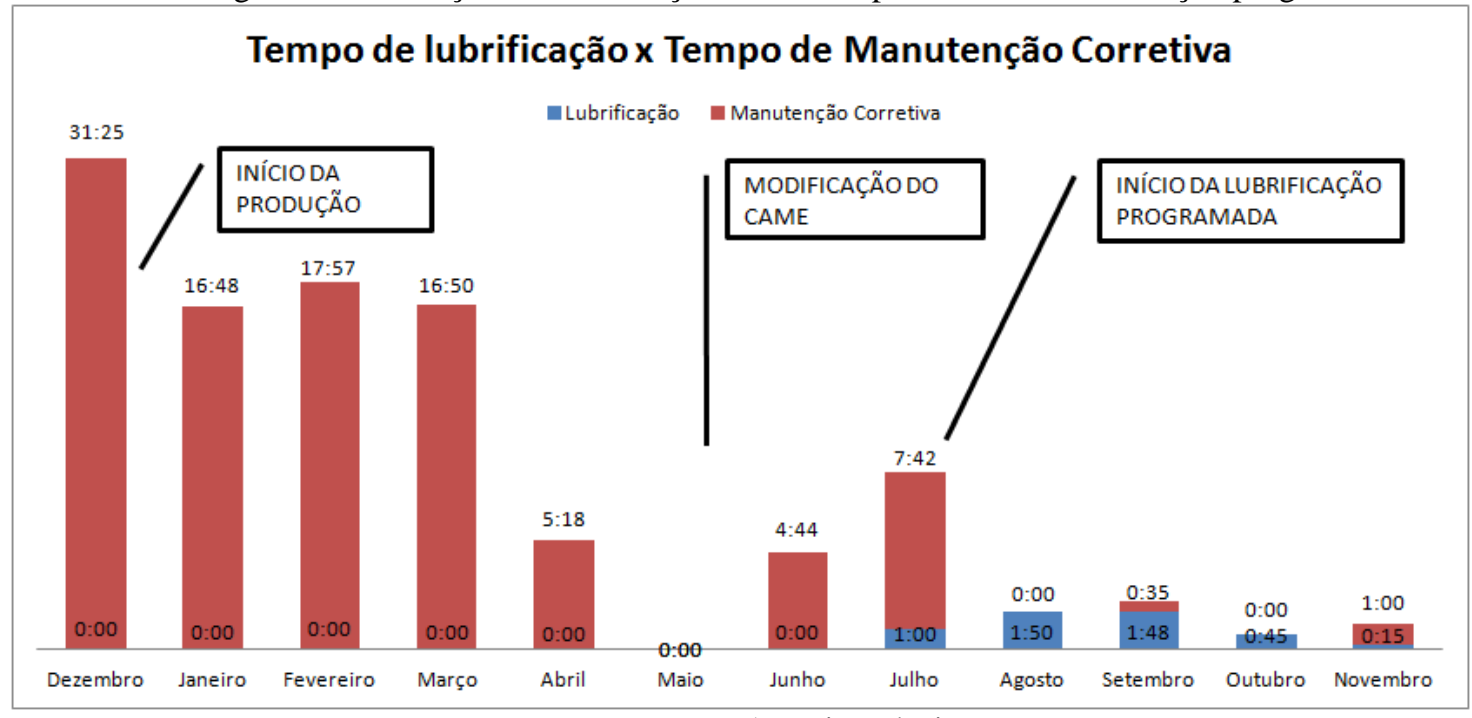

Fonte: Autoria própria

$\mathrm{O}$ valor de forma $\gamma<1$ indica que o equipamento estava na fase de mortalidade infantil indicando falha de projeto do equipamento que após as modificações e ações de melhorias passou para a fase de maturidade $(\gamma<1)$. As três quebras ocorridas após a implementação da lubrificação ocorreram devido à falha no processo de produção, ocorrendo o acúmulo de matéria-prima no conjunto e consequentemente forçando-o até a quebra. $\mathrm{OMTTR}_{2}$ para as 3 quebras ocorridas foi de 2,9 horas. Com isso, a disponibilidade do equipamento passou $A_{1}=96,9 \%$ para $A_{2}=99,8 \%$. Isso significa que para o tempo de máquina programada para produção, o módulo desacelerador de produtos esteve $99,8 \%$ disponível.

$$
A_{2}=\frac{M T T F}{M T T F+M T T R}=\frac{1774}{1774+2,9}=99,8 \%
$$

Apesar de parecer 96,9\% um tempo razoável de disponibilidade, deixa de parecer quando pensamos que a máquina é composta de dezenas de unidades sem redundância que apresentam seu percentual de disponibilidade e que a disponibilidade da máquina é um sistema em série das disponibilidades individuais. Dessa forma, pode-se entender que o aumento da disponibilidade de 96,9\% para $99,8 \%$ é uma conquista significativa, deixando de ser o equipamento com maior impacto na disponibilidade da máquina.

Agora, depois de adquirido maior estabilidade do equipamento, deve-se refazer o ciclo de forma a analisar os dados históricos e novamente analisar os modos de falhas para que novas ações sejam realizadas, que certamente terão ações mais complexas para obter novos resultados positivos, chegando, por exemplo, a reprojeto das guias circulares, ou substituição por similares para aumentar a vida útil e reduzir as frequentes manutenções. 


\begin{abstract}
The maintenance as a strategic part in organizations is directly responsible for the availability of assets and plays an important role in the company's outcomes. The object of study here is a deceleration module used in machinery for producing personal hygiene products for a multinational company located in Rio Grande do Sul, southern Brazil. This production line machine alone presents the larger capacity of the plant, representing $25 \%$ of the monthly production volume, and the corrective maintenance in that module causes significant losses. This study aims to increase the availability and reliability through the Reliability Centered Maintenance (RCM), which is based on the analysis of faults, use of FMEA and the implementation of improvements in order to reduce the occurrence of faults, as well as to ensure the equipment operates at low cost. After analyzing and implementing these actions, the MTTF (Mean Time To Failure) went from 57.7 hours to 1774.0 hours and $\gamma$ from 0.76 to 1.02 , passing the mortality to the maturity stage, without reaching the abrasion stage still in random failures in the production process. Thus, the availability of the equipment went from $96.9 \%$ to $99.8 \%$.
\end{abstract}

Keywords: availability; reliability; FMEA

\title{
Referências
}

BORCHE CASALAS, A. "Métodos numéricos", Porto Alegre: Ed. da UFRGS, 2008.

FOGLIATTO, F. S.; DUARTE, J. L. R. “Confiabilidade e Manutenção Industrial”, Brasil, Elsevier, $1^{\text {a }}$ edição, 2009.

MENDES, A. A. "Manutenção Centrada na Confiabilidade: uma abordagem quantitativa". Dissertação (Mestrado). Universidade Federal do Rio Grande do Sul/PPEGEP. 2011.

MUNIZ, R. P. D. "Requisitos de Mantenabilidade na Execução dos Serviços de Manutenção". Dissertação (Mestrado). Universidade Federal do Rio Grande do Sul/PPGEP. 2010.

NSK. “Catálogo Geral: Rolamentos", Disponível em: http://www.nsk.com.br/catalogo_ geral.zip. Acessado em: $25 / 09 / 2012$

OTANI, M.; MACHADO, W. V. “A Proposta de Desenvolvimento de Gestão da Manutenção Industrial na Busca da Excelência ou Classe Mundial”, Revista Gestão Industrial, v. 04, n. 02, pp. 01-16, 2008.

http://revistas.utfpr.edu.br/pg/index.php/revistagi/article/ view/16/13. Acessado em 12/10/2012.

PEREIRA, M. J. “Engenharia de Manutenção - Teoria e Prática”, Ciência Moderna, Brasil, 1ª edição, 2009.

SELLITTO, M. A. "Formulação estratégica da manutenção industrial com base na confiabilidade dos equipamentos", Revista Gestão Industrial, v. 15, n. 1, pp. 44-59, 2005.

http://www.scielo.br/pdf/prod/v15n1/n1a04.pdf. Acessado em: 18/09/12

THK. “Guia R: Modelo HCR”, Disponível em: https://tech.thk.com/index_pt.html. Acessado em: 30/06/2012.

THK. "Séries de Acessórios de Lubrificação para Sistemas Lineares", Disponível em:

https://tech.thk.com/index_pt.html. Acessado em: 30/06/2012.

THK. "Sistema Linear: Descrição Geral”, Disponível em: https://tech.thk.com/index_ pt.html. Acessado em: $30 / 06 / 2012$.

VIDOR, G. "Diretrizes para Avaliação de Sistemas de Gestão de Poka-yoke”, Dissertação (Mestrado). Universidade Federal do Rio Grande do Sul/PPGEP. 2010. 


\section{Dados dos Autores}

\section{Nome completo: Doglas Stoffel}

Filiação institucional: Universidade Federal do Rio Grande do Sul

Endereço completo para correspondência (bairro, cidade, estado, país e CEP): Rua Gomes Jardim, 1060, apto 103, Bairro Santana - Porto Alegre - RS - Brasil. CEP: 90620-130.

Telefones para contato: (51) 98864876

e-mail: doglasstoffel@gmail.com

Nome completo: Juan Pablo Raggio Quintas

Filiação institucional: Universidade Federal do Rio Grande do Sul

Departamento: Departamento de Engenharia Mecânica

Endereço completo para correspondência (bairro, cidade, estado, país e CEP): Rua Sarmento Leite, $425-1^{\circ}$ Andar. Bairro: Cidade Baixa. Porto Alegre - RS - Brasil. CEP: 90050-170.

Telefones para contato: (51) 3308-3680

e-mail:pablo@ufrgs.br

Submetido em: 07/04/2013

Aceito em: 15/10/2014 